\title{
AVALIAÇÃO DA QUALIDADE FISIOLÓGICA DE SEMENTES DE MAMONEIRA (Ricinus communis L.) PELO TESTE DE TETRAZÓLIO ${ }^{1}$
}

\author{
CAROLINA MARIA GASPAR-OLIVEIRA²; CIBELE CHALITA MARTINS³; JOÃO NAKAGAWA ${ }^{4}$
}

\begin{abstract}
RESUMO - Objetivou-se com esse trabalho estabelecer parâmetros para a avaliação da qualidade fisiológica de sementes de mamoneira (Ricinus communis L.) pelo teste de tetrazólio. Avaliaramse cinco lotes de sementes quanto à viabilidade e ao vigor pelo teste de tetrazólio e os resultados comparados aos obtidos nos testes de germinação em areia, germinação em papel, primeira contagem da germinação em papel, emergência de plântulas em campo, índice de velocidade de emergência, classificação do vigor de plântulas, comprimento das plântulas, massa da matéria seca de plântulas e envelhecimento acelerado. O delineamento experimental empregado foi o inteiramente casualizado, e a comparação de médias realizada pelo teste de Tukey a $5 \%$ de probabilidade. Os resultados de viabilidade do teste de tetrazólio se correlacionaram com o teste de germinação em areia, com a emergência em campo e com o comprimento de plântulas, e os de vigor do teste de tetrazólio com a classificação do vigor de plântulas. Concluiu-se que os parâmetros estabelecidos são eficientes para a avaliação da viabilidade e promissores para a avaliação do vigor de sementes de mamoneira pelo teste de tetrazólio.
\end{abstract}

Termos para indexação: viabilidade, vigor, mamona, metodologia.

\section{EVALUATION OF THE PHYSIOLOGICAL QUALITY OF CASTOR BEAN SEED (Ricinus communis L.) USING THE TETRAZOLIUM TEST}

\begin{abstract}
The object of this study was to establish parameters to evaluate the physiological quality of castor bean seeds (Ricinus communis L.) using the the tetrazolium test. Five seed lots were evaluated for viability and vigor by the tetrazolium test and the results compared with the germination test in sand, on paper, first count of the germination test on paper, seedling emergence in the field, emergence speed index, seedling vigor classification, seedling length and dry matter, and accelerated ageing. The statistical design was completely randomized and the comparison of means was by the Tukey test at the 0.05 level of probability. The tetrazolium test viability results were correlated with the germination test in sand, with seedling emergence in the field and with seedling length, and tetrazolium vigor was correlated with seedling vigor classification. It was concluded that the parameters established are efficient for estimating castor bean seed viability and are promising for evaluating castor bean seed vigor using the tetrazolium test.
\end{abstract}

Index terms: viability, vigor, castor seed, methodology.

\footnotetext{
${ }^{1}$ Submetido em 26/06/2008. Aceito para publicação em 27/01/2009. Parte da Tese de Doutorado do primeiro autor apresentada a UNESP/Faculdade de Ciências Agronômicas/Campus Botucatu.
}

${ }^{2}$ Eng. Agr. Doutora, cmgasparol@gmail.com
${ }^{3}$ Professora colaboradora, Departamento de Produção Vegetal/Agricultura, FCA/UNESP, cibele@fca.unesp.br

${ }^{4}$ Professor Titular aposentado voluntário, Departamento de Produção Vegetal/Agricultura, FCA/UNESP, secdamv@fca.unesp.br 


\section{INTRODUÇÃO}

A utilização do teste de tetrazólio para estabelecer a qualidade fisiológica das sementes está condicionada à avaliação da intensidade e da distribuição da coloração nas diferentes estruturas da semente. Os tecidos vivos e vigorosos, geralmente túrgidos, colorem-se de maneira lenta e uniforme e apresentam coloração rosa ou vermelha, brilhante e limpa, bem superficial. Os tecidos em deterioração permitem maior intensidade de difusão da solução de tetrazólio nas membranas celulares danificadas, e caracterizam-se por colorirem mais rápido e escuro que os tecidos normais, apresentando coloração vermelha escura. A ausência de coloração identifica tecidos mortos, que não apresentam atividade enzimática suficiente para a produção do formazan. Esses tecidos normalmente são flácidos e de cor branca opaca, mas podem ser amarelados, cinzentos ou esverdeados e ainda com pontuações ou manchas avermelhadas, dependendo da presença de fungos, bactérias ou compostos formados durante a deterioração (Delouche et al., 1976; França Neto et al., 1998).

Além da coloração, na interpretação dos resultados do teste de tetrazólio também devem ser observadas a turgescência dos tecidos, a ausência de fraturas ou lesões nas regiões vitais, danos causados por insetos e a formação morfológica da semente. Deve ser considerada, ainda, a região de transição entre os tecidos normais e os tecidos mortos ou deteriorados, bem como a extensão e localização das regiões coloridas e descoloridas (França Neto et al., 1998).

Para a determinação de níveis de vigor pelo teste de tetrazólio, efetua-se a separação das sementes em diferentes classes durante a interpretação. Para as sementes de soja, feijão vagem e algodão (França Neto et al., 1998; Bhering et al., 1996; Vieira e Von pinho, 1999) foram estabelecidas oito classes. Nesses casos, a soma das porcentagens de sementes incluídas nas classes 1 a 3 expressa os resultados do vigor; a soma das classes 1 a 5 , a viabilidade. As sementes pertencentes às classes 6 a 8 não são viáveis. Por outro lado, a Association of Official Seed Analystis - AOSA (1983) recomenda a interpretação do teste procurando enquadrar as sementes em três classes; as classes 1 e 2 representam as sementes viáveis e a 3, as não-viáveis; nesse caso, as da classe 1 são computadas para a avaliação do vigor. Esse procedimento foi adotado para a interpretação de testes conduzidos com sementes de milho, café, amendoim e tomate (Dias e Barros, 1999; Dias e Silva, 1998; Bittencourt e Vieira, 1999; Santos et al., 2007).
Em sementes de mamoneira, as Regras para Análise de Sementes (Brasil, 1992) recomendam para a avaliação da viabilidade de Ricinus sp considerar a semente viável aquela com o embrião e endosperma coloridos, podendo o endosperma apresentar pequenas necroses na superfície, desde que não estejam em contato com o embrião. Já, de acordo com Grabe (1976), a avaliação da viabilidade de sementes de mamoneira deve ser realizada segundo os parâmetros do grupo "outras dicotiledôneas não leguminosas", por ele estabelecidos, segundo os quais uma semente é viável quando as estruturas do embrião estão bem desenvolvidas, intactas e apresentam coloração vermelha após a exposição ao sal de tetrazólio. Além disso, a semente viável pode apresentar pequenas necroses nos cotilédones, em outras áreas que não sejam a junção do eixo embrionário e dos cotilédones, ou pequenas necroses na ponta extrema da radícula.

Essas recomendações para mamoneira são pouco específicas, e são escassas na descrição dos danos e em figuras e/ou fotos, o que dificulta a avaliação da viabilidade das sementes, a padronização do teste e não possibilita a classificação dos lotes em níveis de vigor. Portanto, a padronização do teste de tetrazólio para avaliação da viabilidade e do vigor de sementes de mamoneira irá expandir a utilização pelas empresas e laboratórios de análise de sementes, que devido à demanda, necessitam de um método rápido de avaliação da qualidade dessas sementes. Assim, objetivou-se com esse trabalho estabelecer parâmetros para a avaliação da viabilidade e do vigor de sementes de mamoneira pelo teste de tetrazólio.

\section{MATERIAL E MÉTODOS}

Neste trabalho foram utilizados cinco lotes de sementes de mamoneira, cultivar AL Guarany 2002, procedentes da região de Campinas/SP e Presidente Prudente/SP, numerados de 1 a 5 , homogeneizados e amostrados em $2.000 \mathrm{~g}$ cada um, para a realização das análises (Brasil, 1992).

O teste de tetrazólio foi executado para todos os lotes com quatro repetições de 50 sementes, que foram pré-condicionadas com tegumento entre papel toalha de germinação, previamente umedecido com 2,5 vezes a massa (g) do papel em água destilada, dobrado em quatro e colocado dentro de sacos plásticos de $0,05 \mathrm{~mm}$ de espessura, para manter a umidade, por 18 horas a $30^{\circ} \mathrm{C}$ (Moore, 1985; Brasil, 1992; França Neto et al., 1998). Após esse período, o tegumento foi removido e as sementes cortadas longitudinal 
e medianamente, no sentido do comprimento, através do endosperma e embrião, selecionando-se a metade que possibilitou a melhor visualização das estruturas internas de cada uma delas (Gaspar-Oliveira et al, 2009). As amostras foram colocadas em copos plásticos e imersas na solução de tetrazólio a $0,2 \%$, mantidas em câmara de germinação a $35^{\circ} \mathrm{C}$, na ausência de luz, por 120 minutos, de acordo com a metodologia para o teste de tetrazólio em sementes de mamoneira adequada por Gaspar-Oliveira (2007).

As sementes foram analisadas minuciosamente com o objetivo de identificar alterações nos tecidos das sementes viáveis que possibilitassem a classificação das sementes quanto à viabilidade e ao vigor pelo teste de tetrazólio. As considerações da classificação foram baseadas nos parâmetros estabelecidos por Bittencourt e Vieira (1999), Vieira e Von Pinho (1999), e Santos et al. (2007), em sementes de amendoim, algodão e tomate, respectivamente, adaptados para as características morfológicas das estruturas das sementes de mamoneira e, também, nas recomendações das Regras para Análise de Sementes (Brasil, 1992) e de Grabe (1976) para esta espécie.

Assim, as sementes foram divididas em três classes: Classe 1: viáveis e vigorosas; Classe 2: viáveis e não vigorosas e Classe 3: não viáveis, determinando-se a porcentagem de sementes em cada uma delas, calculando em seguida, o potencial de vigor (Classe 1) e o potencial de germinação ou viabilidade (somatório da porcentagem de sementes das Classes 1 e 2).

Os resultados de viabilidade e vigor dos lotes pelo teste de tetrazólio foram comparados e correlacionados estatisticamente com outros testes de avaliação da qualidade. Assim, para todos os lotes avaliaram-se a germinação e o vigor pelos testes:

Germinação em areia, realizado com oito repetições de 25 sementes, semeadas entre areia esterilizada (EA), previamente umedecida com água destilada, na proporção de $50 \%$ da capacidade de retenção (Brasil, 1992). O teste foi conduzido em caixas acrílicas transparentes $(110 \mathrm{~mm}$ x $110 \mathrm{~mm} \times 35 \mathrm{~mm}$ ), sendo utilizadas duas por repetição, acondicionadas em sacos plásticos $(0,033 \mathrm{~mm}$ de espessura) para a manutenção da umidade, sob alternância de temperatura e luz $\left(20^{\circ} \mathrm{C} / 16\right.$ horas e $30^{\circ} \mathrm{C} / 8$ horas sob luz $)$. No $14^{\circ}$ dia após a instalação do teste, contabilizaram-se as plântulas normais, anormais, as sementes mortas e as duras. As sementes duras foram escarificadas com lixa d'água número 80 e colocadas para germinar por mais sete dias, em rolo de papel toalha (RP), umedecido com 2,5 vezes a massa (g) do papel em água destilada, sob mesma alternância de temperatura, para verificação da sua viabilidade.

No teste de germinação em papel foram semeadas oito repetições de 25 sementes, em rolos de papel toalha (RP), umedecidos com 2,5 vezes a massa (g) do papel em água destilada, acondicionados em sacos plásticos $(0,033 \mathrm{~mm}$ de espessura) para a manutenção da umidade e dispostos na posição horizontal em germinador, sob alternância de temperatura e luz $\left(20{ }^{\circ} \mathrm{C} / 16\right.$ horas e $30{ }^{\circ} \mathrm{C} / 8$ horas sob luz), realizando-se a primeira contagem e a retirada das plântulas normais aos sete dias após a instalação do teste (Brasil, 1992). No $14^{\circ}$ dia contabilizaram-se as plântulas normais, anormais, sementes mortas e duras. A viabilidade das sementes duras foi verificada adotando-se o mesmo procedimento descrito no teste de germinação em areia.

$\mathrm{Na}$ emergência de plântulas em campo foram utilizadas quatro repetições de 50 sementes por lote, semeadas diretamente no solo, a $5 \mathrm{~cm}$ de profundidade, no espaçamento de $20 \mathrm{~cm}$ entre linhas, dentro de túnel plástico, com irrigação controlada. Consideraram-se plântulas emersas aquelas em que os cotilédones saíram do solo e estavam abertos, aos 21 dias após a semeadura. Em conjunto com este teste foi conduziu-se o índice de velocidade de emergência de plântulas (IVE), contabilizando-se diariamente o número de plântulas emersas até os 21 dias após a semeadura, e calculando-se pela fórmula proposta por Maguire (1962).

No teste de envelhecimento acelerado as sementes foram colocadas em camada única sobre tela em caixas acrílicas transparentes $(110 \mathrm{~mm} \times 110 \mathrm{~mm} \times 35 \mathrm{~mm})$, contendo $40 \mathrm{ml}$ de água, fechadas, envoltas com saco plástico $(0,033 \mathrm{~mm}$ de espessura), e mantidas a $42^{\circ} \mathrm{C}$ por 24 horas, em câmara de germinação sem controle de umidade. Após esse período seguiu-se o teste de germinação, com oito repetições de 25 sementes em rolo de papel toalha (RP), umedecido com 2,0 vezes a massa ( $\mathrm{g}$ ) do papel em água, mantido em temperatura constante de $25{ }^{\circ} \mathrm{C}$ por 14 dias, quando a contagem das plântulas normais foi realizada (Vieira e Carvalho, 1994; Souza et al., 2007).

A classificação do vigor de plântulas foi realizada em conjunto com o teste de germinação em areia. Após 14 dias da instalação do teste efetuou-se a avaliação das plântulas, que foram classificadas em normais fortes (vigorosas), para aquelas com as estruturas essenciais bem formadas e maiores que as demais; e normais fracas (pouco vigorosas), para as bem formadas, porém menores que as anteriores e pouco desenvolvidas (Figura 1) (Nakagawa, 1999). A porcentagem foi calculada sobre o total de sementes instaladas no teste, ou seja, 25 sementes para cada uma das quatro repetições. 


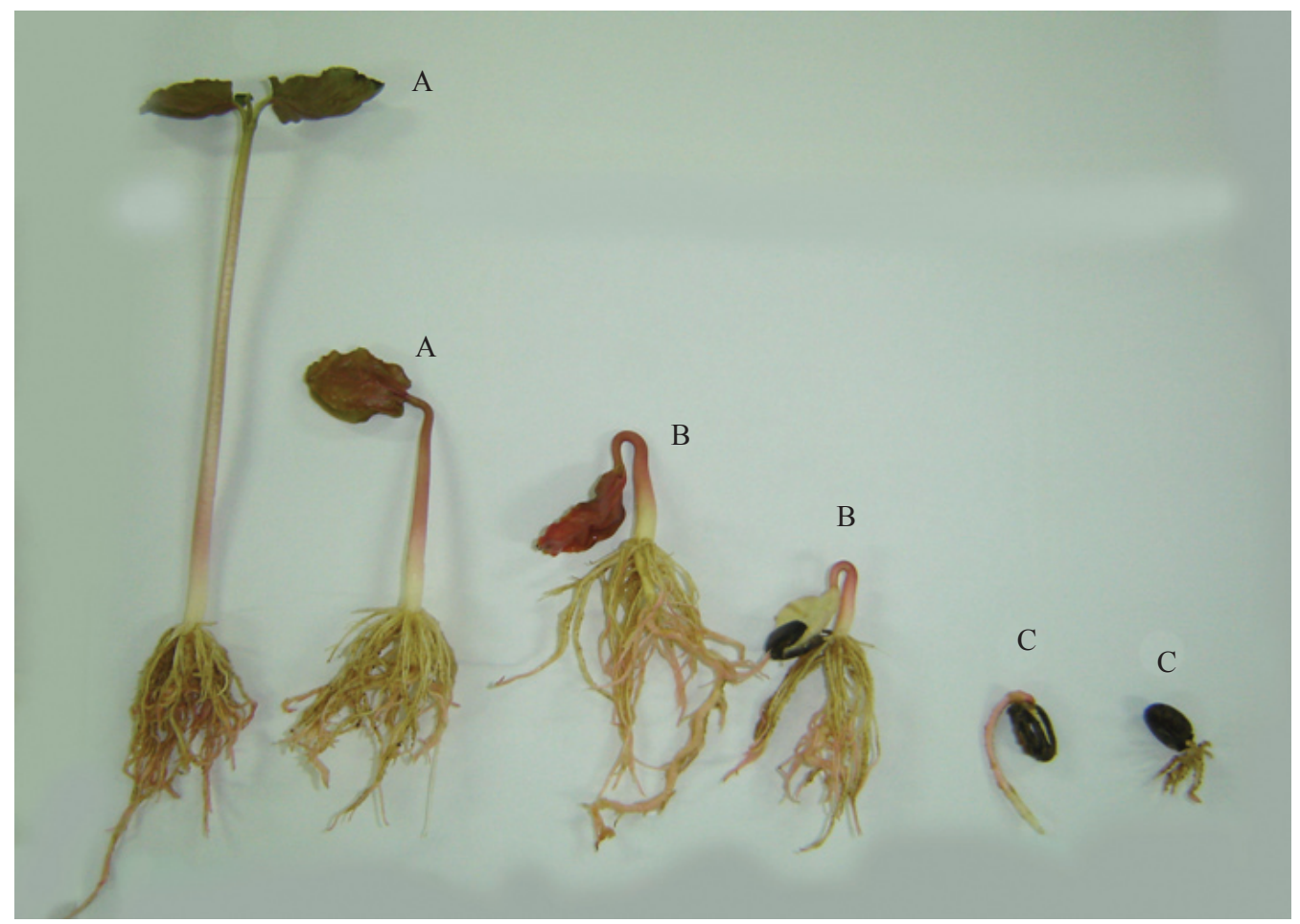

FIGURA 1. Classificação do vigor de plântulas de mamoneira em normais fortes (a), normais fracas (b), e anormais (c).

O comprimento de plântulas foi realizado com quatro repetições de dez sementes, instaladas sobre uma linha traçada no terço superior do papel toalha para germinação, pré-umedecida com 2,5 vezes a massa (g) do papel em água destilada. Os rolos de papel foram colocados em posição vertical na câmara de germinação e acondicionados em sacos plásticos $(0,033 \mathrm{~mm}$ de espessura) para evitar a desidratação (Vieira e Carvalho, 1994). O teste foi conduzido em temperatura constante de $30{ }^{\circ} \mathrm{C}$ por sete dias, quando foram realizadas as avaliações do comprimento da radícula (da extremidade da radícula até o hipocótilo) e total das plântulas normais (da extremidade da radícula até a inserção dos cotilédones) com régua em milímetros. O cálculo do comprimento das plântulas foi obtido dividindo-se o resultado total pelo número de sementes do teste (Nakagawa, 1999; Vanzolini et al., 2007).

$\mathrm{Na}$ avaliação da massa da matéria seca de plântulas, as plântulas normais do teste de comprimento tiveram os tecidos de reserva removidos com bisturi e foram colocadas dentro de sacos de papel para secar em estufa de circulação de ar a $80{ }^{\circ} \mathrm{C}$ por 24 horas (Nakagawa, 1999). Após esse período, as amostras foram pesadas, e calculou-se a massa da matéria seca de plântula (mg/plântula), mediante a divisão da massa total pelo número de plântulas do teste.

$\mathrm{O}$ teor de água foi determinado pelo método da estufa a $105{ }^{\circ} \mathrm{C} \pm 3{ }^{\circ} \mathrm{C}$ por 24 horas (Brasil, 1992), utilizando duas repetições de 15 sementes.

$\mathrm{Na}$ análise estatística de todos os testes, o delineamento experimental empregado foi o inteiramente casualizado e as médias foram comparadas pelo teste de Tukey a $5 \%$ de probabilidade. Os resultados de viabilidade e vigor dos lotes, obtidos pelo teste de tetrazólio, foram comparados com os resultados dos demais testes realizados, mediante análise de correlação simples (Pimentel - Gomes, 1973). Nos testes em que se utilizaram oito repetições de 25 sementes, as mesmas foram agrupadas antes das análises, formando quatro repetições de 50 sementes.

\section{RESULTADOS E DISCUSSÃO}

$\mathrm{Na}$ avaliação da qualidade fisiológica pelo teste de tetrazólio, as sementes foram classificadas em viáveis e vigorosas, viáveis e não vigorosas e não viáveis, sendo:

Classe 1 - viáveis e vigorosas: os parâmetros para classificar as sementes de mamoneira, apresentados na Figura 2, foram: 


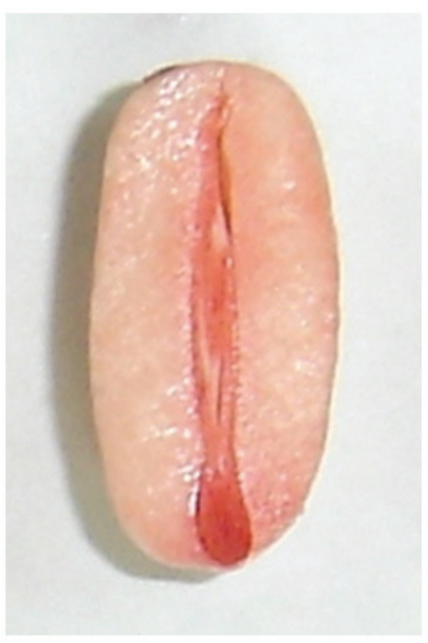

1

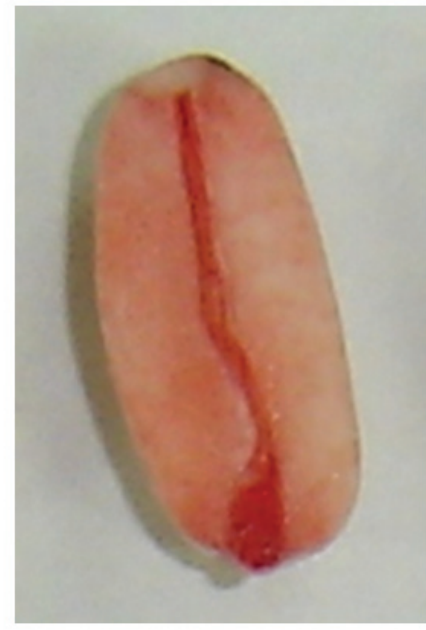

2

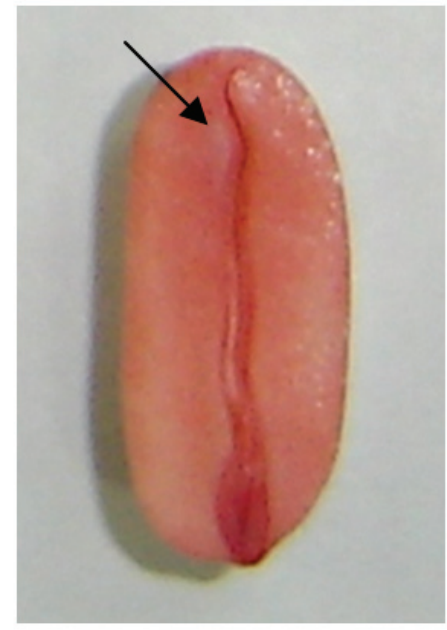

3

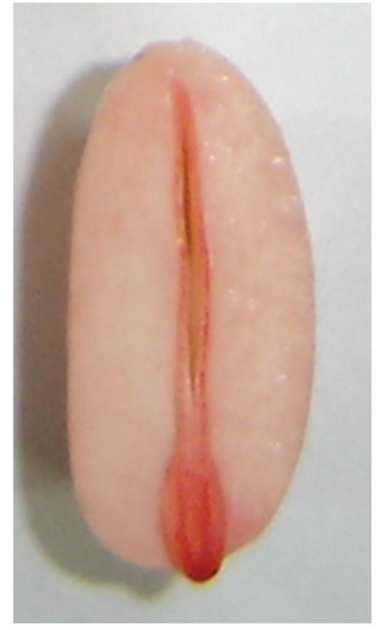

4

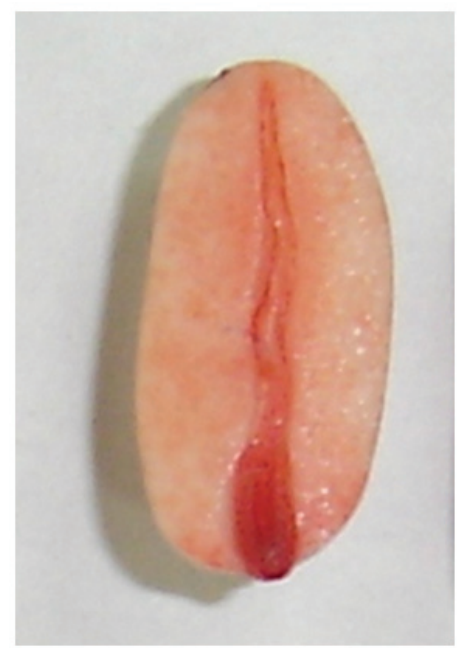

5

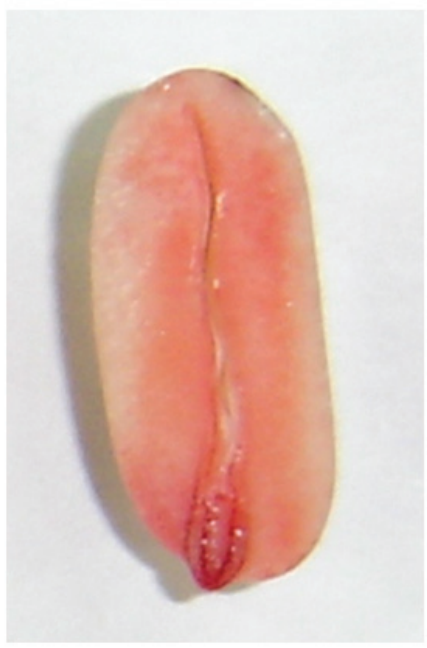

6

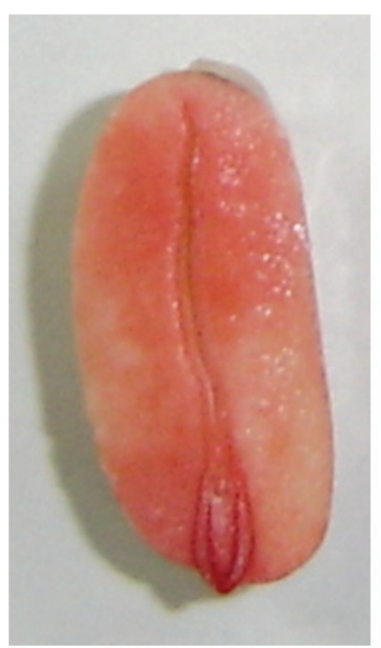

7

FIGURA 2. Sementes viáveis e vigorosas de mamoneira $(1,2,3,4,5,6$ e 7 - ver descrição no texto).

1 - Sementes com coloração rosa-claro a rosa em toda a extensão do embrião e do endosperma, com tecidos firmes e túrgidos, sem lesões visíveis;

2, 3 - Sementes com pequenos danos superficiais em volta dos cotilédones, mas sem atingi-los;

4 - Sementes com coloração fraca, indicando restrição à penetração da solução de tetrazólio, mas com os tecidos túrgidos;

5 - Sementes com coloração vermelha carmim (tecido em deterioração) na extremidade apical inferior do eixo hipocótilo radícula;

6, 7 - Sementes com áreas de coloração rosa-escuro a vermelho carmim no endosperma, mas com o tecido túrgido e brilhante.
Classe 2 - viáveis e não vigorosas: os parâmetros para classificar as sementes de mamoneira, apresentados na Figura 3, foram:

1, 2, 3, 4 - Sementes que apresentavam endosperma e/ou cotilédones com menos de $50 \%$ das áreas não coloridas;

5 - Sementes apresentando a extremidade do eixo hipocótilo-radícula sem coloração, mas com os tecidos firmes e túrgidos, sem lesões visíveis, com possibilidade de originar plântulas normais, através do desenvolvimento das raízes secundárias;

6, 7, 8 - Sementes com endosperma e/ou embrião com coloração vermelho carmim-escura, porém brilhante e sem alteração de textura; 


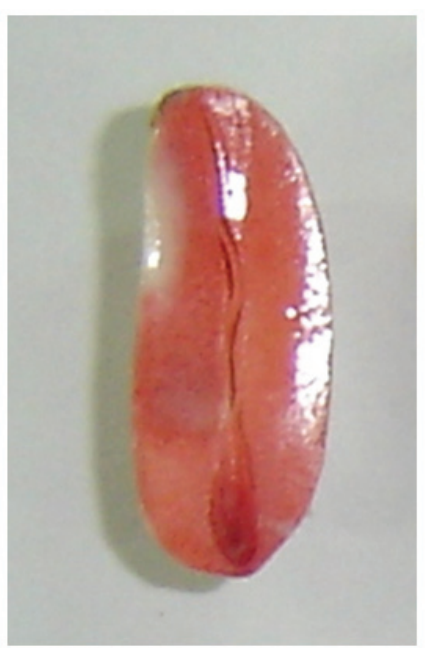

1

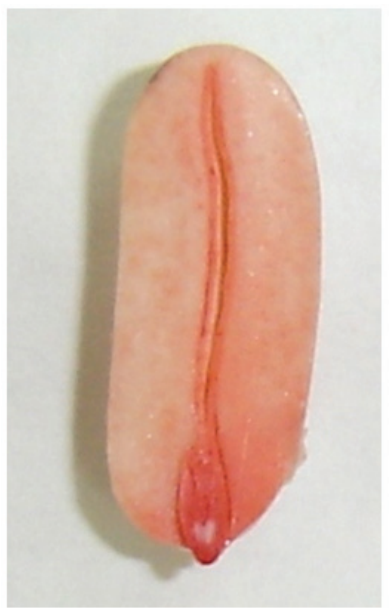

5

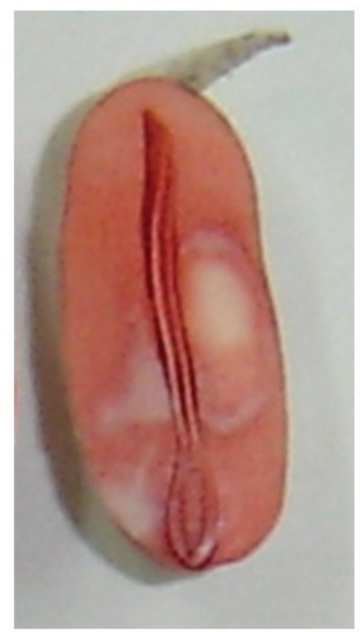

9

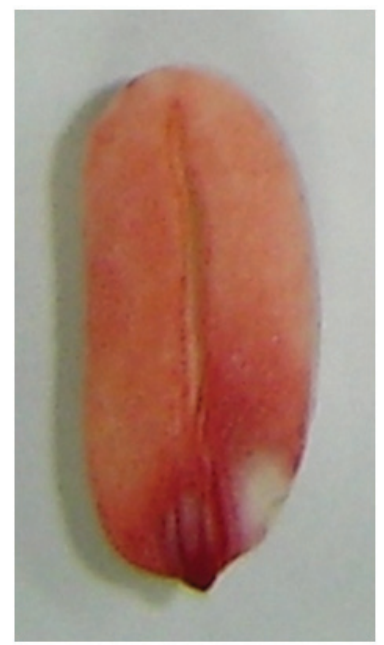

2

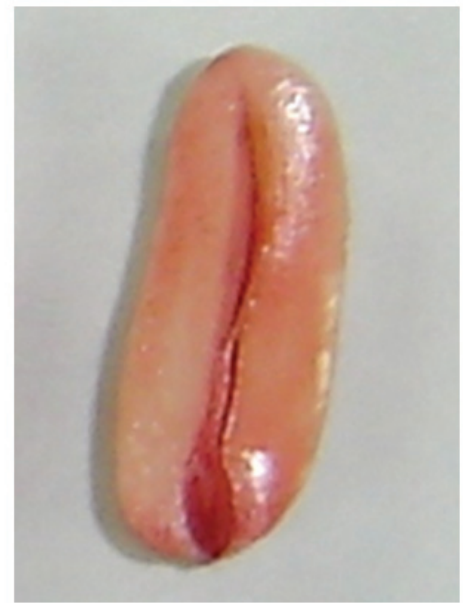

6

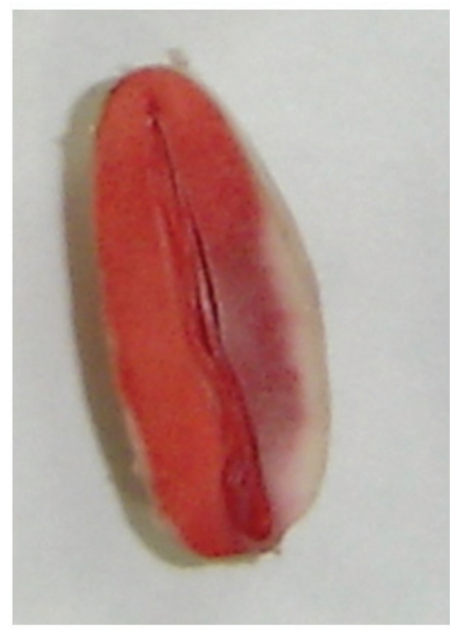

10

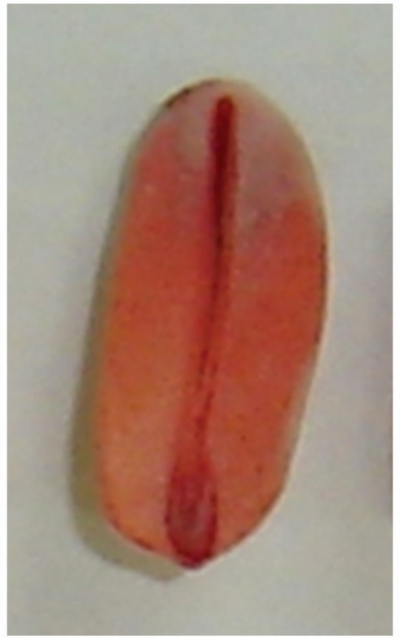

3

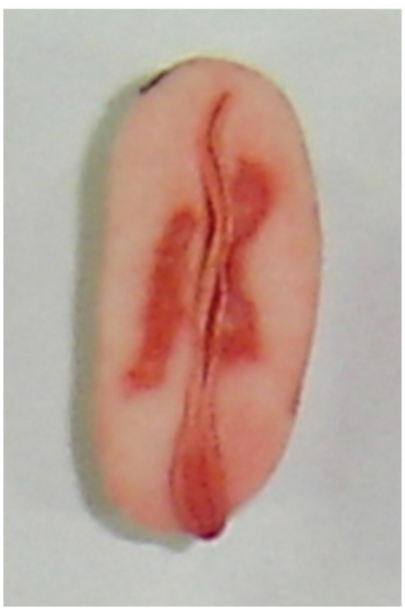

7

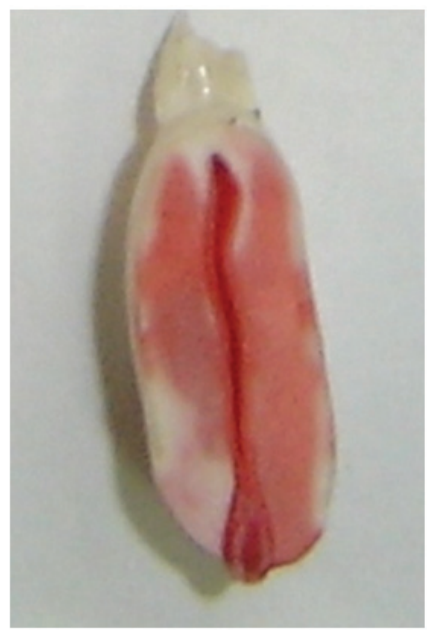

11

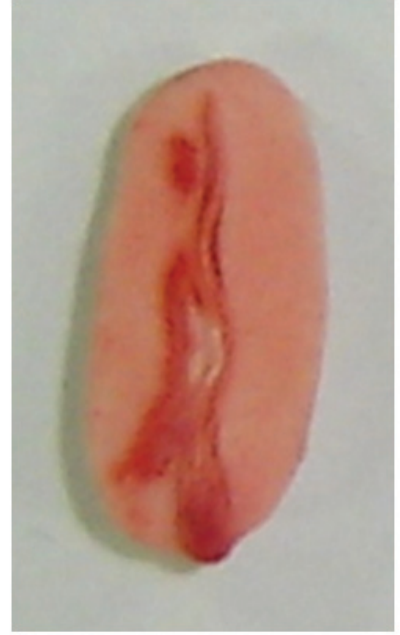

4

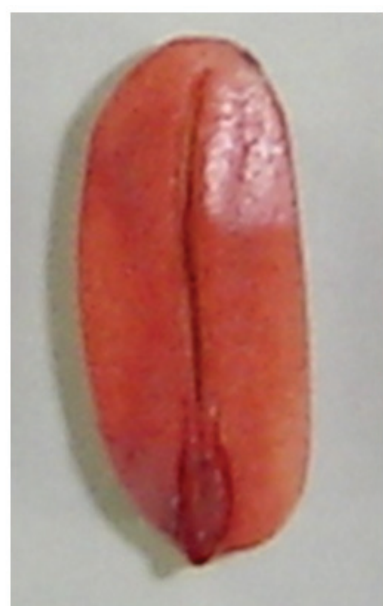

8

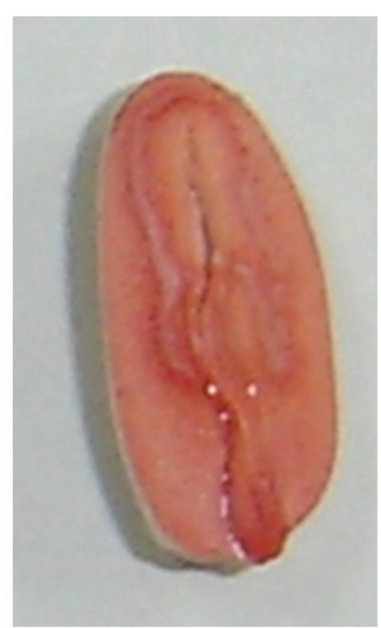

12

FIGURA 3. Sementes viáveis e não vigorosas de mamoneira $(1,2,3,4,5,6,7,8,9,10,11$ e 12 - ver descrição no texto). 
9, 10, 11, 12 - Sementes que só teriam possibilidade de germinar sob condições extremamente favoráveis, pois poderão apresentar crescimento mais lento, raízes secundárias e/ou ausência de um cotilédone devido aos danos no embrião.

Classe 3 - não viáveis: os parâmetros para classificar as sementes de mamoneira, apresentados na Figura 4, foram:

1, 2 - Sementes com mais de $50 \%$ das áreas dos cotilédones e/ou endosperma não coloridas;

3, 4, 5 - Sementes apresentando ausência de coloração na região do eixo hipocótilo-radícula, com tecidos flácidos e brancos ou amarelados;

6, 7, 8 - Sementes com áreas do endosperma e embrião totalmente sem coloração, indicando a possibilidade de originarem plântulas anormais, ou ainda apresentando estado metabólico característico de sementes mortas.

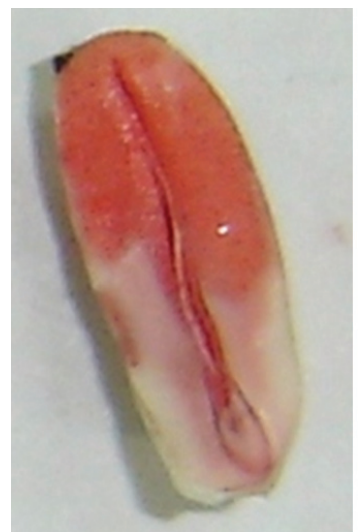

1

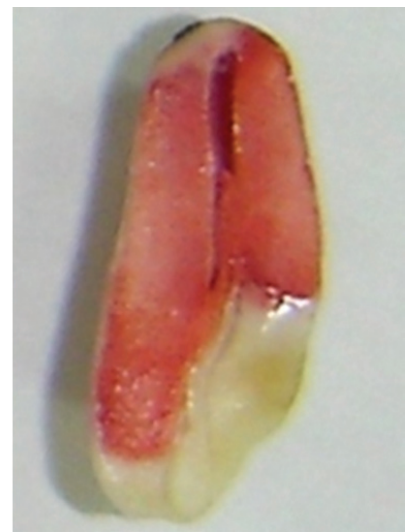

2

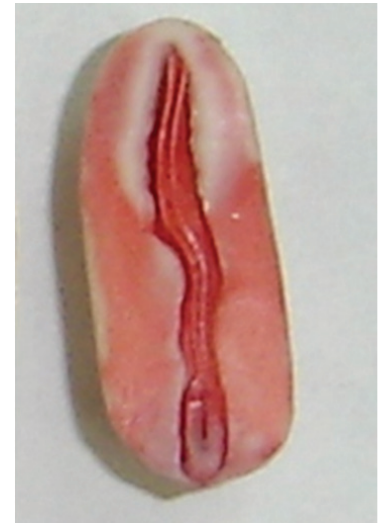

3

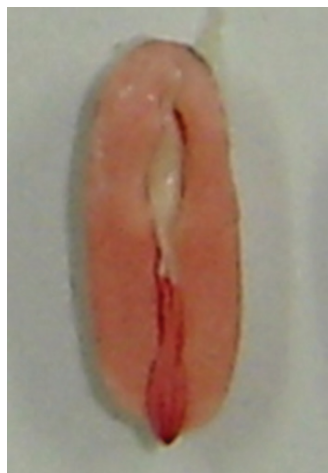

6

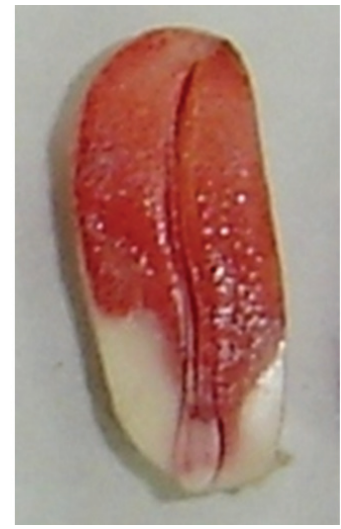

4

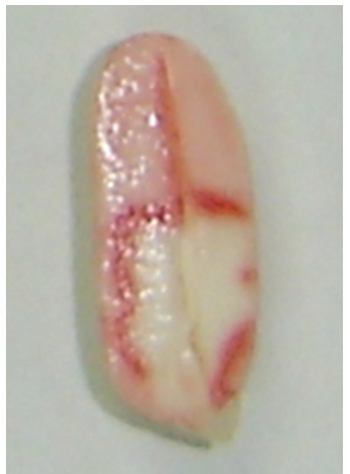

7

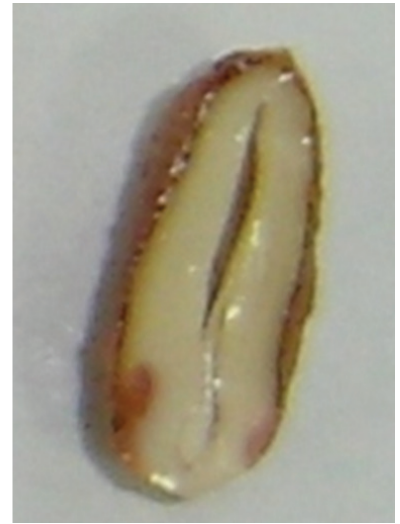

5

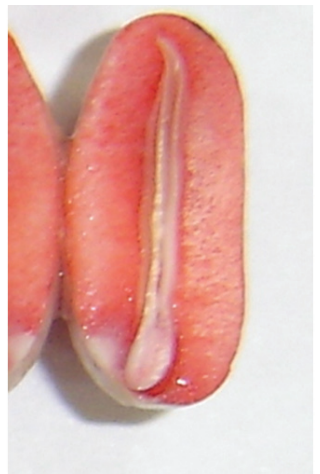

8

FIGURA 4. Sementes não viáveis de mamoneira $(1,2,3,4,5,6,7$ e 8 - ver descrição no texto). 
Os resultados da comparação de médias dos testes que avaliaram a qualidade fisiológica das sementes de mamoneira encontram-se na Tabela 1. Na avaliação da viabilidade o teste de tetrazólio destacou a superioridade dos lotes 1,2 e 3 em relação aos lotes 4 e 5 (Tabela 1). Resultados semelhantes foram observados para o teste de germinação em areia, já a germinação em papel não diferenciou estatisticamente os lotes. Na análise de correlação simples (Tabela 2) verifica-se que a viabilidade pelo teste de tetrazólio se correlacionou significativamente com o teste de germinação em areia, emergência em campo, comprimento de plântulas e massa da matéria seca de plântulas.

TABELA 1. Resultados das avaliações de teor de água (TA), teste de tetrazólio, germinação em papel (GP), germinação entre areia (GA), emergência de plântulas em campo (EC), índice de velocidade de emergência (IVE), normais fortes da classificação das plântulas (NF), primeira contagem da germinação (PC), envelhecimento acelerado (EA), comprimento de plântulas (CP) e massa de matéria seca de plântulas (MS), de cinco lotes de sementes de mamoneira.

\begin{tabular}{|c|c|c|c|c|c|c|c|c|c|c|c|c|c|}
\hline \multirow[b]{2}{*}{ Lotes } & \multicolumn{3}{|c|}{ Teste de tetrazólio } & \multirow[b]{2}{*}{$\mathrm{GP}(\%)$} & \multirow[b]{2}{*}{$\mathrm{GA}(\%)$} & \multirow[b]{2}{*}{$\mathrm{EC}(\%)$} & \multirow[b]{2}{*}{ IVE } & \multirow[b]{2}{*}{$\mathrm{NF}(\%)$} & \multirow[b]{2}{*}{$\mathrm{PC}(\%)$} & \multirow[b]{2}{*}{ EA $(\%)$} & \multicolumn{2}{|c|}{$\mathrm{CP}(\mathrm{cm})$} & \multirow{2}{*}{$\begin{array}{l}\text { MS (mg/ } \\
\text { plântula) }\end{array}$} \\
\hline & TA $(\%)$ & $\begin{array}{c}\text { Viabilidade } \\
(\%)\end{array}$ & $\begin{array}{l}\text { Vigor } \\
(\%)\end{array}$ & & & & & & & & Total & Raiz & \\
\hline 1 & $5,0 \mathrm{~B}^{1}$ & $99 \mathrm{AB}$ & $66 \mathrm{~A}$ & $86 \mathrm{~A}$ & $93 \mathrm{~A}$ & $91 \mathrm{~A}$ & $8,4 \mathrm{~A}$ & $70 \mathrm{~A}$ & $51 \mathrm{~B}$ & $60 \mathrm{C}$ & $10,2 \mathrm{AB}$ & $7,3 \mathrm{AB}$ & $54,0 \mathrm{~A}$ \\
\hline 2 & $5,1 \mathrm{~B}$ & $100 \mathrm{~A}$ & $52 \mathrm{~B}$ & $82 \mathrm{~A}$ & $96 \mathrm{~A}$ & $87 \mathrm{AB}$ & $7,6 \mathrm{~A}$ & $62 \mathrm{AB}$ & $51 \mathrm{~B}$ & $62 \mathrm{BC}$ & $14,5 \mathrm{~A}$ & $11,2 \mathrm{~A}$ & $80,1 \mathrm{~A}$ \\
\hline 3 & $5,7 \mathrm{~A}$ & $99 \mathrm{AB}$ & $49 \mathrm{~B}$ & $87 \mathrm{~A}$ & $92 \mathrm{~A}$ & $92 \mathrm{~A}$ & 8,4 & 5 & $60 \mathrm{AB}$ & $84 \mathrm{~A}$ & $9,6 \mathrm{AB}$ & $7,5 \mathrm{AB}$ & $62,9 \mathrm{~A}$ \\
\hline 4 & $5,2 \mathrm{~B}$ & $95 \mathrm{BC}$ & $54 \mathrm{AB}$ & $78 \mathrm{~A}$ & $81 \mathrm{~B}$ & $87 \mathrm{AB}$ & $8,4 \mathrm{~A}$ & 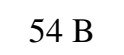 & $64 \mathrm{~A}$ & $72 \mathrm{~B}$ & $5,8 \mathrm{~B}$ & $3,8 \mathrm{~B}$ & $37,7 \mathrm{~A}$ \\
\hline 5 & $5,1 \mathrm{~B}$ & $4 \mathrm{C}$ & $56 \mathrm{AB}$ & $82 \mathrm{~A}$ & $80 \mathrm{~B}$ & $81 \mathrm{~B}$ & $7,6 \mathrm{~A}$ & $60 \mathrm{AB}$ & $55 \mathrm{AB}$ & $68 \mathrm{BC}$ & $7,3 \mathrm{~B}$ & $5,2 \mathrm{~B}$ & $45,5 \mathrm{~A}$ \\
\hline $\mathrm{CV} \%$ & 1,4 & 2,2 & 10,5 & 6,2 & 4,1 & 4,0 & 7,4 & 11,2 & 10,2 & 7,2 & 28,9 & 31,2 & 34,9 \\
\hline DMS & 0,3 & 4,7 & 12,7 & 11,2 & 7,9 & 7,6 & 1,3 & 14,5 & 12,6 & 10,9 & 6,0 & 4,8 & 42,7 \\
\hline
\end{tabular}

${ }^{1}$ Médias seguidas da mesma letra maiúscula na coluna não diferem entre si pelo teste de Tukey, a 5\% de probabilidade.

TABELA 2. Coeficientes simples (r) entre as médias dos testes de viabilidade e vigor pelo teste de tetrazólio (TZ), germinação em papel (GP), germinação entre areia (GA), emergência de plântulas em campo (EC), índice de velocidade de emergência (IVE), normais fortes da classificação das plântulas (NF), primeira contagem da germinação (PC), envelhecimento acelerado (EA), comprimento de plântulas (CP) e massa de matéria seca plântulas (MS), realizados para cinco lotes de sementes de mamoneira.

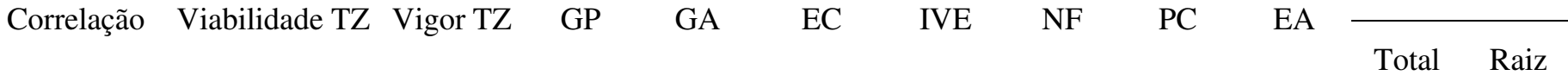

\begin{tabular}{|c|c|c|c|c|c|c|c|c|c|c|c|}
\hline Vigor TZ & $0,07^{\mathrm{ns}}$ & & & & & & & & & & \\
\hline GP & $0,55^{\mathrm{ns}}$ & $0,17^{\mathrm{ns}}$ & & & & & & & & & \\
\hline GA & $1,00 * *$ & $0,07^{\mathrm{ns}}$ & $0,58^{\mathrm{ns}}$ & & & & & & & & \\
\hline $\mathrm{EC}$ & $0,72 *$ & $0,10^{\mathrm{ns}}$ & $0,61^{\mathrm{ns}}$ & $0,71^{\mathrm{ns}}$ & & & & & & & \\
\hline IVE & $0,11^{\mathrm{ns}}$ & $0,20^{\mathrm{ns}}$ & $0,35^{\mathrm{ns}}$ & $0,09^{\mathrm{ns}}$ & $0,76^{*}$ & & & & & & \\
\hline NF & $0,34^{\mathrm{ns}}$ & $0,86^{* *}$ & $0,16^{\mathrm{ns}}$ & $0,35^{\mathrm{ns}}$ & $0,00^{\mathrm{ns}}$ & $-0,21^{\mathrm{ns}}$ & & & & & \\
\hline $\mathrm{PC}$ & $-0,53^{\mathrm{ns}}$ & $-0,49^{\mathrm{ns}}$ & $-0,33^{\mathrm{ns}}$ & $-0,55^{\mathrm{ns}}$ & $0,06^{\mathrm{ns}}$ & $0,52^{\mathrm{ns}}$ & $-0,84^{\mathrm{ns}}$ & & & & \\
\hline EA & $-0,19^{\mathrm{ns}}$ & $-0,69^{\mathrm{ns}}$ & $0,27^{\mathrm{ns}}$ & $0,18^{\mathrm{ns}}$ & $0,25^{\mathrm{ns}}$ & $0,43^{\mathrm{ns}}$ & $-0,90^{\mathrm{ns}}$ & $0,73 *$ & & & \\
\hline CP Total & $0,87 * *$ & $-0,05^{\mathrm{ns}}$ & $0,30^{\mathrm{ns}}$ & $0,87 * *$ & $0,28^{\mathrm{ns}}$ & $-0,40^{\mathrm{ns}}$ & $0,41^{\mathrm{ns}}$ & $-0,73^{\mathrm{ns}}$ & $-0,39^{\mathrm{ns}}$ & & \\
\hline CP Raiz & $0,87 * *$ & $-0,13^{\mathrm{ns}}$ & $0,35^{\mathrm{ns}}$ & $0,88 * *$ & $0,30^{\mathrm{ns}}$ & $-0,38^{\mathrm{ns}}$ & $0,32^{\mathrm{ns}}$ & $-0,69^{\mathrm{ns}}$ & $-0,29^{\mathrm{ns}}$ & $0,99 * *$ & \\
\hline MS & $0,85^{* *}$ & $-0,28^{\mathrm{ns}}$ & $0,36^{\mathrm{ns}}$ & $0,86^{* *}$ & $0,32^{\mathrm{ns}}$ & $-0,36^{\mathrm{ns}}$ & $0,17^{\mathrm{ns}}$ & $-0,58^{\mathrm{ns}}$ & $-0,14^{\mathrm{ns}}$ & $0,97 * *$ & $0,99 * *$ \\
\hline
\end{tabular}

${ }^{\text {ns }}$ não significativo; $*$ significativo a $10 \%$; ** significativo a $1 \%$. 
Dessa maneira, pode-se afirmar que os parâmetros estabelecidos para o teste de tetrazólio são eficientes para avaliar a viabilidade de sementes de mamoneira, já que se observou semelhança entre os resultados obtidos por esse teste e entre a germinação e emergência de plântulas em campo.

Para o potencial de vigor, o teste de tetrazólio destacou o lote 1 como superior aos lotes 2 e 3 , sem diferenciá-los dos lotes 4 e 5 (Tabela 1). O teste de classificação de plântulas (normais fortes) também apresentou a mesma tendência para os lotes. Esses testes também apresentaram correlação significativa entre si (Tabela 2). A emergência de plântulas em campo também destacou o lote 1 como superior, mas não houve diferença entre este e os lote 3, 2 e 4 (Tabela 1). Dentre os testes de vigor, a emergência em campo apresentou correlação significativa (Tabela 2) somente com o IVE, que de forma semelhante ao teste de massa da matéria seca de plântulas não diferenciou estatisticamente os lotes pela comparação de médias (Tabela 1).

A primeira contagem da germinação e o envelhecimento acelerado apresentaram classificação dos lotes diferente dos demais testes (Tabela 1), e também não se correlacionaram com nenhum outro teste, apenas entre si (Tabela 2). De acordo com Marcos Filho (1999), o teste de envelhecimento acelerado, como depende da influência de vários fatores, pode indicar um potencial para uma amostra que algumas vezes não é confirmado na prática. Assim, esse teste foi considerado inadequado para estimar a qualidade dos lotes de sementes de mamoneira utilizados nesta pesquisa.

Entre os testes utilizados para a avaliação da qualidade dos lotes de sementes, nem todos realizaram a mesma classificação para os lotes, como pôde ser visto comparandose os resultados dos testes de classificação de plântulas, emergência de plântulas em campo e comprimento de plântulas (Tabela 1). Os três testes avaliam características semelhantes das sementes, porém em condições totalmente diferentes. Assim, é preciso considerar que os testes de vigor oferecem apenas comparações entre o potencial fisiológico das sementes, não permitindo estimar o comportamento destas sob as mais variadas condições de ambiente e que, por isso, é conveniente a tomada de decisões baseada na interpretação conjunta dos resultados de dois ou três testes, cujos princípios estejam intimamente relacionados aos objetivos que se deseja atingir (Marcos Filho et al., 1987).

Outros pesquisadores também constataram que amostras de sementes classificadas nas categorias intermediárias podem apresentar comportamento semelhante ao das sementes de alto vigor ou das de vigor mais baixo, dependendo do método empregado na sua avaliação (Marcos Filho et al., 1987; Marcos Filho, 1999; Vieira e Carvalho, 1994; Bittencourt, 1995).

Os resultados do teste de germinação conduzido em papel e em areia apresentaram uma diferença maior que $5 \%$ entre si e também quando comparados com os do teste de tetrazólio. Porém, aqueles resultados podem ter sido mascarados pelo excessivo desenvolvimento de fungos, observado durante a condução dos testes. Outros autores também verificaram diferenças maiores que $5 \%$ entre os resultados do teste de tetrazólio e do teste padrão de germinação em sementes de soja, amendoim e algodão, quando estas se encontraram infectadas por fungos (França Neto et al., 1998; Bittencourt, 1995; Santos et al., 1992).

Assim, quanto à estimativa do vigor das sementes de mamoneira pelo teste de tetrazólio, pode-se afirmar que o teste é promissor, pois foi eficiente em diferenciar lotes que o teste de germinação não havia diferenciado que é um dos objetivos de um teste de vigor, e também se correlacionou com o teste de classificação de plântulas que é um teste realizado em conjunto com a germinação e dessa forma de fácil padronização. Entretanto, apesar do vigor pelo tetrazólio não ter se correlacionado com a emergência em campo, cabe ressaltar que este teste não se correlacionou com nenhum outro teste de vigor, além do IVE, e somente com a germinação em areia, indicando que provavelmente as condições de campo eram favoráveis, e não tenham provocado estresse nas sementes (Vieira et al., 1994).

Dessa maneira, considerando o potencial do teste de tetrazólio para avaliar o vigor de sementes de mamoneira apresentado por este estudo, e os resultados positivos encontrados nos trabalhos conduzidos com outras espécies como o amendoim (Bittencourt e Vieira, 1999), soja (França Neto et al., 1998), milho (Dias e Barros, 1999), algodão (Vieira e Von Pinho, 1999), tomate (Santos et al., 2007) e feijão-de-vagem (Bhering et al., 1996), que concluíram que o teste de tetrazólio é eficiente para estimar o vigor das sementes, recomenda-se que sejam realizados outros estudos, relacionando-o também a outros testes de avaliação de vigor.

\section{CONCLUSÕES}

Os parâmetros estabelecidos para a avaliação da qualidade fisiológica das sementes de mamoneira pelo teste de tetrazólio são eficientes para estimar a viabilidade e promissores para avaliação do vigor, necessitando por isso de estudos adicionais relacionados ao vigor. 


\section{REFERÊNCIAS}

ASSOCIATION OF OFFICIAL SEED ANALYSTS - AOSA. Seed vigor testing handbook. East Lansing, 1983. 93p. (Contribution, 32).

BHERING, M.C.; SILVA, R.F.; ALVARENGA, E.M.; DIAS, D.C.F.S.; PENA, M.F. Avaliação da viabilidade e do vigor das sementes de feijão-de-vagem (Phaseolus vulgaris L.) pelo teste de tetrazólio. Viçosa: UFV, 1996. $27 \mathrm{p}$.

BITTENCOURT, S.R.M.de. Avaliação da qualidade fisiológica de sementes de amendoim através do teste de tetrazólio. 1995, 111f. Dissertação (Mestrado em Agronomia) - Faculdade de Ciências Agrárias e Veterinárias - Universidade Estadual Paulista, Jaboticabal, 1995.

BITTENCOURT, S.R.M. de; VIEIRA, R.D. Metodologia do teste de tetrazólio em sementes de amendoim. In: Vigor de Sementes: conceitos e testes. KRZYZANOWSKI, F.C.; VIEIRA, R.D. e FRANÇA NETO, J.B. Londrina: ABRATES, 1999. p. 8.2-1 a 8.2-8.

BRASIL, Ministério da Agricultura e Reforma Agrária. Secretaria Nacional de Defesa Agropecuaria. Departamento Nacional de Produção Vegetal. Coordenação de Laboratório Vegetal. Regras para análise de sementes. Brasília, DF, 1992. 365p.

DELOUCHE, J.C.; STILL, T.W.; RASPET, M.; LIENHARD, M. O teste de tetrazólio para viabilidade da semente. Brasília, DF: AGIPLAN, 1976. 103p.

DIAS, M.C.L.L.; BARROS, A.S.R. Metodologia do teste de tetrazólio em sementes de milho. In: Vigor de Sementes: conceitos e testes. KRZYZANOWSKI, F.C.; VIEIRA, R.D. e FRANÇA NETO, J.B. Londrina: ABRATES, 1999. p. 8.4-1 a 8.4-10.

DIAS, M.C.L.L.; SILVA, W.R. Teste de tetrazólio em sementes de café. Londrina: IAPAR, 1998, 16p. Boletim técnico n55. (IAPAR. Boletim técnico, 59).

FRANÇA NETO, J.B.; KRZYZANOWSKI, F.C.; COSTA, N.P. da. O teste de tetrazólio em sementes de soja. Londrina: EMBRAPA-CNPSo, 1998. 72p. (EMBRAPACNPSo. Documentos, 116).

GASPAR-OLIVEIRA, C. M. Avaliação da qualidade fisiológica de sementes de mamoneira (Ricinus communis L.) pelo teste de tetrazólio. 2007, 96f. Tese (Doutorado em Agronomia) - Faculdade de Ciências Agronômicas - Universidade Estadual Paulista, Botucatu, 2007.
GASPAR-OLIVEIRA, C.M.; MARTINS, C.C.; NAKAGAWA, J. Métodos de preparo das sementes de mamoneira para o teste de tetrazólio. Revista Brasileira de Sementes, v.31, n.1, p.160-167, 2009.

GRABE, D.F. Manual do teste de tetrazólio em sementes. Ministério da Agricultura. AGIPLAN. 1976. 86p.

MAGUIRE, J.D. Speed of germination-aid in selection and evaluation for seedling emergence and vigor. Crop Science, v. 2, n.1, p. 176-177, 1962.

MARCOS FILHO, J. Teste de envelhecimento acelerado. In: Vigor de Sementes: conceitos e testes. KRZYZANOWSKI, F.C.; VIEIRA, R.D.; FRANÇA NETO, J.B. Londrina: ABRATES, 1999. p.3-1 a 3-24.

MARCOS FILHO, J. CÍCERO, S. M., SILVA, W. R. Avaliação da qualidade das sementes. Piracicaba: FEALQ, 1987. 230p.

MOORE, R.P. Handbook on tetrazolium testing. Zurich: ISTA, 1985, 99p.

NAKAGAWA, J. Testes de vigor baseados no desempenho das plântulas. In: Vigor de Sementes: conceitos e testes. KRZYZANOWSKI, F.C.; VIEIRA, R.D.; FRANÇA NETO, J.B. Londrina: ABRATES, 1999. p. 2-1 a 2-24.

PIMENTEL - GOMES, F. Curso de estatística experimental. Piracicaba: Escola Superior de Agronomia "Luiz de Queiroz", 1973. 430p.

SANTOS, M.A.O; NOVEMBRE, A.D.L.C.; MARCOS FILHO, J. Tetrazolium test to assess viability and vigour of tomato seeds. Seed Science and Technology, v. 35, n. 1, p. 213-223, 2007.

SANTOS, V.L.M. dos; BANCI, C.A.; CALIL，A.C.; MENDOZA, R.M.; SILVA, R.F. da; SANTOS, C.M.dos. Utilização do teste de tetrazólio na avaliação da germinação e do vigor de sementes de algodão (Gossypium hirsutum L.), como um teste complementar ao teste padrão de germinação. Revista Brasileira de Sementes, v. 14, n. 2, p. 155-159, 1992.

SOUZA, S. A.; CAVARIANI, C.; NAKAGAWA, J. Accelerated aging test in castor seeds (Ricinus communis L.). In: ISTA Congress 28.; Congresso Brasileiro de Sementes, 15., 2007, Foz do Iguaçu. Anais... Foz do Iguaçu, 2007. p. 117.

VANZOLINI, S.; ARAKI, C.A.S.; SILVA, A.C.T.M.; NAKAGAWA, J. Soybean length test in the evaluation of the physiological quality of soybean seeds. In: ISTA CONGRESS 28.; Congresso Brasileiro de Sementes, 15., 2007, Foz do Iguaçu. Anais... Foz do Iguaçu, 2007. p.107. 
VIEIRA, M.G.G.C.; VON PINHO, E.V.R. Metodologia do teste de tetrazólio em sementes de algodão. In: Vigor de Sementes: conceitos e testes. KRZYZANOWSKI, F.C.; VIEIRA, R.D. \& FRANÇA NETO, J.B. Londrina: ABRATES, 1999. p. 8.1-1 a 8.1-13.
VIEIRA, R.D.; CARVALHO, N.M. Testes de vigor em sementes. Jaboticabal: FUNEP, 1994. 164p.

VIEIRA, R.D.; CARVALHO, N.M.; SADER, R. Testes de vigor e suas possibilidades de uso. In: VIEIRA, R.D.; CARVALHO, N.M. Testes de vigor em sementes. Jaboticabal: FUNEP, 1994. p. 31-47. 